\title{
Paediatric Urolithiasis an Emerging Concern: Single Centre Experience in a Non-Endemic Region in South India
}

\section{Krishna M. B.Vijayaraghavan, MS*; Rohan Rajendran, MS, MCh;Appu Thomas, MS, MCh;Anil Mathew, MD, DNB}

Amrita Institute of Medical Sciences and Research Center, Kochi, Kerala, India

\section{${ }^{*}$ Corresponding author}

Krishna M. B.Vijayaraghavan, MS

Senior Resident, Department of Urology, Amrita Institute of Medical Sciences and Research Center, Kochi, Kerala, India; ; ORCID: 0000-0002-1922-5344; E-mail: krish.stanes@gmail.com

\section{Article Information}

Received: January 19 $9^{\text {th }}$, 202I; Accepted: February It, 202I; Published: February $3^{\text {rd }}$, 202I

\section{Cite this article}

Vijayaraghavan KMB, Rajendran R, Thomas A, Mathew A. Paediatric urolithiasis an emerging concern: Single centre experience in a non-endemic region in South India. Urol Androl Open J. 202I; 5(I): I-6. doi: I0.17I40/UAOJ-5-136

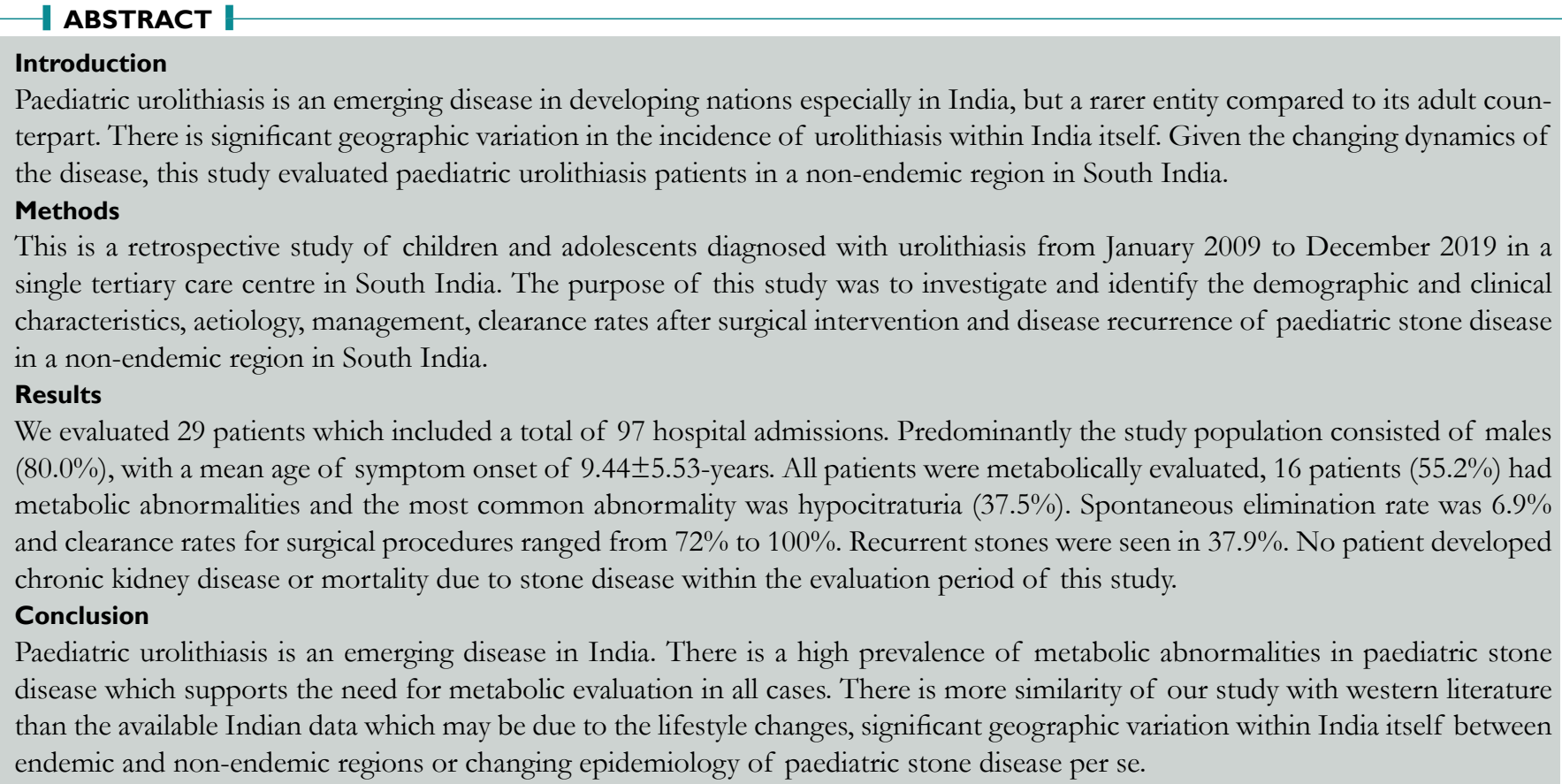

ABSTRACT |

Introduction

Paediatric urolithiasis is an emerging disease in developing nations especially in India, but a rarer entity compared to its adult counterpart. There is significant geographic variation in the incidence of urolithiasis within India itself. Given the changing dynamics of the disease, this study evaluated paediatric urolithiasis patients in a non-endemic region in South India.

\section{Methods}

This is a retrospective study of children and adolescents diagnosed with urolithiasis from January 2009 to December 2019 in a single tertiary care centre in South India. The purpose of this study was to investigate and identify the demographic and clinical characteristics, aetiology, management, clearance rates after surgical intervention and disease recurrence of paediatric stone disease in a non-endemic region in South India.

Results

We evaluated 29 patients which included a total of 97 hospital admissions. Predominantly the study population consisted of males $(80.0 \%)$, with a mean age of symptom onset of $9.44 \pm 5.53$-years. All patients were metabolically evaluated, 16 patients $(55.2 \%)$ had metabolic abnormalities and the most common abnormality was hypocitraturia (37.5\%). Spontaneous elimination rate was $6.9 \%$ and clearance rates for surgical procedures ranged from $72 \%$ to $100 \%$. Recurrent stones were seen in $37.9 \%$. No patient developed chronic kidney disease or mortality due to stone disease within the evaluation period of this study.

\section{Conclusion}

Paediatric urolithiasis is an emerging disease in India. There is a high prevalence of metabolic abnormalities in paediatric stone disease which supports the need for metabolic evaluation in all cases. There is more similarity of our study with western literature than the available Indian data which may be due to the lifestyle changes, significant geographic variation within India itself between endemic and non-endemic regions or changing epidemiology of paediatric stone disease per se.

\section{Keywords}

Paediatrics; Urolithiasis; Urinary tract infection (UTI).

\section{INTRODUCTION}

$\mathrm{U}$ rolithiasis is considered a disease of adults. It also occurs in the paediatric age group but rarer compared to adults. There is significant geographic variation in the incidence of urolithiasis within India itself. The incidence of paediatric urolithiasis in the United States ranges between 1 in 1000 and 1 in 7600 hos- pital admissions. ${ }^{1,2}$ While the frequency of childhood urolithiasis is steadily decreasing in developed countries, it is still prevalent in some regions of the world. Several articles have reported the high prevalence of paediatric urolithiasis in developing countries. ${ }^{3}$ Due to westernisation and change in lifestyle, more stone disease in children are being reported in India in recent times, but there is a paucity of data and articles to report the same. ${ }^{2}$ The purpose 
of this study was to investigate and identify the demographic and clinical characteristics, aetiology, management, clearance rates after surgical intervention and disease recurrence of paediatric stone disease in a non-endemic region in South India.

\section{METHODS}

This is a retrospective study of children and adolescents diagnosed with urolithiasis admitted under the Department of Urology in a single tertiary care centre in South India, from January 2009 to December 2019. The data were obtained from medical records and included those with diagnosis confirmed by imaging (ultrasound, computed tomography (CT), simple abdominal radiography) with or without outpatient follow-up. From the patient records department, we obtained the following information: demographics, family history of urolithiasis, previous signs and symptoms and/ or those present upon diagnosis, findings on physical examination, systemic disease and/or associated anatomical abnormalities, laboratory tests and imaging, location, size and composition of the stones, metabolic disorder diagnosis, urolithiasis treatment and recurrent episodes. Patients who had more than one hospitalization in the period were counted only once. Four patients were excluded because there was no confirmation of urolithiasis, as well as those without proper metabolic workup, as well as those with other systemic illnesses and previous diagnosis of chronic kidney disease. All patients underwent metabolic study at least one month after diagnosis of urolithiasis while they were asymptomatic and on a regular diet with normal physical activity. Patients included in the study were evaluated according to our institute protocol. We obtained one 24-hour urine samples followed by a blood sample. In the 24-hour urine and/or single urine sample we analysed creatinine, calcium, citrate, uric acid, cystine, magnesium, oxalate, and phosphate. The blood sample was analysed for serum creatinine, uric acid, calcium, phosphorus, magnesium, sodium, chlorine, potassium, $\mathrm{pH}$, bicarbonate and parathyroid hormone $(\mathrm{PTH})$. Standard laboratory tests were ordered from the hospital laboratory to analyse the elements in the 24-hour urine, single urine and blood samples. The reference values for defining abnormal urinary excretion of the studied elements were adapted from previous publications. ${ }^{2-4}$ The stone composition was determined using infrared spectroscopy. Where applicable, Continuous variables were expressed as mean \pm standard deviation or $\mathrm{n}(\%)$, while categorical variables were expressed as frequency and proportions. The collected data were compiled and analysed using Microsoft Excel 2018.

\section{RESULTS}

In our study, we evaluated 29 patients which included a total of 97 hospital admissions (some patients required more than one hospitalisation). Predominantly the study population consisted of males $(80.0 \%)$, with a mean age of symptom onset of $9.44 \pm 5.53$ years, from different parts of South India. Four patients $(13.7 \%)$ had a family history of urolithiasis out of which two patients $(6 \%)$ had a family history of paediatric urolithiasis (Table 1). A total of $75 \%$ of patients with metabolic changes had a positive family history.

\begin{tabular}{|llc|}
\hline \multicolumn{2}{l}{ Table I. Patient Characteristics } \\
\hline \multicolumn{2}{|c|}{ Characteristics } & \multicolumn{1}{c|}{$\mathbf{n ( \% )}$} \\
\hline \multirow{2}{*}{ Gender } & Male & $24(82.8 \%)$ \\
\cline { 2 - 3 } & Female & $5(17.2 \%)$ \\
\hline Age (years) of symptom onset & Mean \pm SD & $9.44 \pm 5.53$ \\
\hline \multirow{2}{*}{ Family History } & Yes & $4(13.8 \%)$ \\
\cline { 2 - 3 } & No & $25(86.2 \%)$ \\
\hline
\end{tabular}

Nonspecific abdominal pain (34.5\%), classic renal colic $(31.0 \%)$ and urinary tract infection $(17.2 \%)$ were the most common clinical manifestations prior to diagnosis (Table 2). Hematuria $(82.7 \%)$ and leukocyturia $(65.5 \%)$ were the most commonly found changes in the urinary sediment exam. Urinary tract infection (UTI) was present on initial presentation in 5 patients $(17.2 \%)$, more in the male gender. The main organism was Escherichia coli (40.0\%) and Enterococcus fecalis (40.0\%).

\begin{tabular}{|c|c|}
\hline \multicolumn{2}{|c|}{ Table 2. Clinical Presentation } \\
\hline Clinical Presentation & $n(\%)$ \\
\hline Abdominal pain & $10(34.5 \%)$ \\
\hline Classic renal colic & $9(31.0 \%)$ \\
\hline Urinary infection & $5(17.2 \%)$ \\
\hline Macroscopic hematuria & $3(10.3 \%)$ \\
\hline Microscopic hematuria & $2(6.9 \%)$ \\
\hline Urinary symptoms & $2(6.9 \%)$ \\
\hline Others & I(3.4\%) \\
\hline
\end{tabular}

\section{Imaging Investigations Done to Detect Stones}

Abdominal ultrasonography in 28 patients $(96.5 \%)$, abdomen X-ray in $15(51.7 \%)$, non-contrast abdominal CT scan in $13(44.8 \%)$, intravenous urography $7(24.1 \%)$, voiding cystourethrogram in 1 $(3.4 \%)$, renal scintigraphy in $6(20.6 \%)$. As for the stone location, 14 patients (48.2\%) had ureteral stones, $13(44.8 \%)$ renal, 1 (3.4\%) bladder and $1(3.4 \%)$ urethral stone. The average stone size was $13.2 \pm 7.0 \mathrm{~mm}$. Bilateral disease was seen in $6(20.6 \%)$ patients and Nephrocalcinosis was seen in $1(3.4 \%)$ patients. Hydronephrosis/ Hydroureteronephrosis was found in 17 patients $(58.6 \%)$ and vesicoureteric reflux in $2(6.8 \%)$. As for the location of stones $86 \%$ were upper urinary tract stones, $4 \%$ were lower urinary tract stones and $10 \%$ were upper along with lower urinary tract stones (Table 3). Stone analysis was done in 11 patients $(37.9 \%)$ out of which, $81.8 \%$ was calcium oxalate and calcium phosphate, 9\% magnesium ammonium phosphate and 9\% urate stones. Anatomic abnormalities occurred in 5 patients (17.2\%), and among them, pelviureteric junction obstruction was the most common. All patients were metabolically evaluated, 16 patients $(55.2 \%)$ had metabolic abnormalities. Most common abnormality was hypocitraturia 6 patients $(37.5 \%)$ followed by hypercalciuria 5 patients $(31.2 \%)$, hyperoxaluria 3 patients $(18.7 \%)$ and hyperuricosuria 2 patients $(12.5 \%)$. There was one case each of renal tubular acidosis (type 1 ) and hyperphosphaturia. Two cases of hyperoxaluria were diagnosed to have primary hyperoxaluria and they both were siblings. Our 


\begin{tabular}{|lcccccc}
\hline \multicolumn{2}{l}{ Table 3. Stone Location a Comparative Analysis } \\
\hline \multicolumn{1}{l}{ Country } & \multicolumn{1}{l}{ Authors } & Period & $\begin{array}{c}\text { Age } \\
\text { (years) }\end{array}$ & $\begin{array}{c}\text { Upper Urinary } \\
\text { Tract (\%) }\end{array}$ & $\begin{array}{c}\text { Lower Urinary } \\
\text { Tract (\%) }\end{array}$ & $\begin{array}{c}\text { Upper+Lower } \\
\text { Urinary Tract (\%) }\end{array}$ \\
\hline Pakistan & Rizvi et al $^{6}$ & $1987-2000$ & $0-14$ & 69 & 31 & \\
\hline United Kingdom & Coward et al $^{13}$ & $1997-2001$ & $0-15$ & 90 & 4 & 6 \\
\hline Turkey & Bak et al $^{12}$ & $1998-2008$ & $0-16$ & 78 & 18 & 4 \\
\hline Netherlands & Rellum et a $^{15}$ & $1996-2010$ & $0-19$ & 76 & 12 & 12 \\
\hline India & Current study & $2009-2019$ & $0-18$ & 86 & 4 & 10 \\
\hline
\end{tabular}

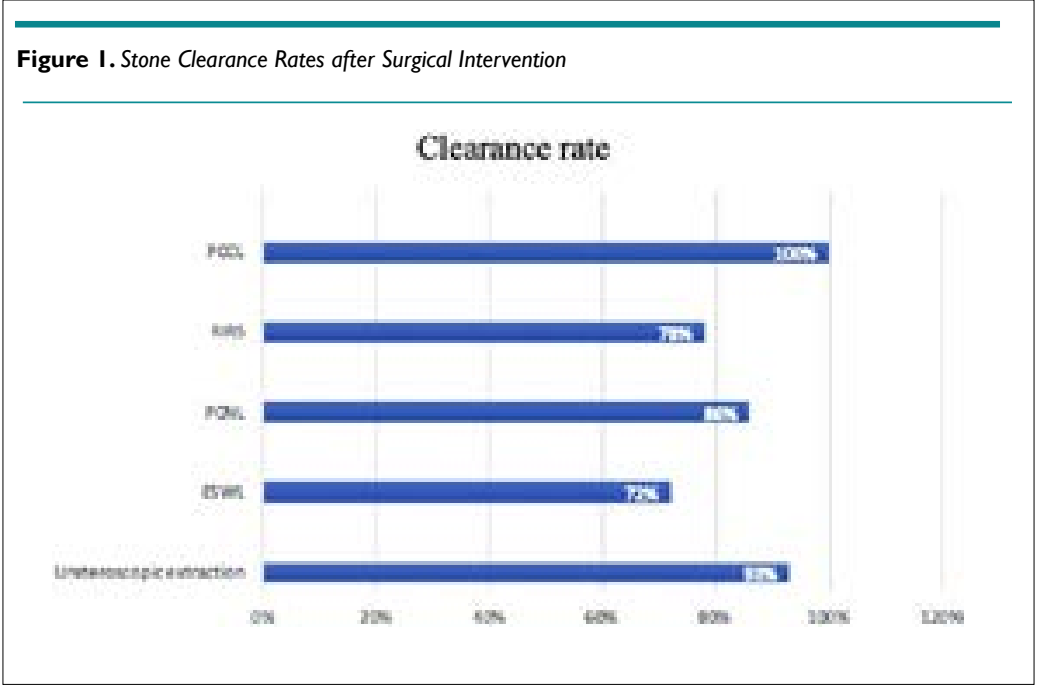

study reported a spontaneous elimination rate of $6.9 \%$. Among the surgical procedures done, $6 \%$ underwent open/Laparoscopic surgery, 24.1\% extracorporeal lithotripsy (ESWL), 48.2\% had ureteroscopic extraction, $3.4 \%$ percutaneous nephrolithotomy (PCNL), 10.3\% had retrograde intra-renal surgery (RIRS) and 7\% had percutaneous cystolitholapaxy (PCCL). Clearance rates for following procedures are, ureteroscopic extraction 93\%, ESWL $72 \%$, PCNL $86 \%$, PCCL 100\%, and RIRS 78\% respectively (Figure 1). Pharmacological treatment was instituted in $75 \%$ of the patients in our study group to prevent recurrent stone disease. Recurrent stones were seen in 11(37.9\%), among them 8 (72.7\%) of them had metabolic disorders and $3(27.2 \%)$ patients had no metabolic changes. No patient developed chronic kidney disease or mortality due to stone disease within the evaluation period of this study.

\section{DISCUSSION}

Paediatric urolithiasis is a fairly less explored subset of urolithiasis. Paediatric urolithiasis carries more morbidity and disruption to quality of life as compared to adult counterparts. The varied and vague symptoms at presentation of paediatric stone disease cause delay in diagnosis and treatment. It is associated more with metabolic disorders/abnormalities and an increased chance of recurrence compared to adult stone disease. ${ }^{5,6}$. Recent literature reports reveal a significant increase in stone disease in the paediatric population which is attributed to change in lifestyle and food habits, paediatric obesity and the advent of better imaging modalities. ${ }^{1-3}$ Given the increased prevalence and changing dynamics of the disease, this study evaluated paediatric patients with urolithiasis admitted to a tertiary care hospital to help in the understanding of the paediatric stone disease.

In our study, we observed that the average age of presentation (mean 9.44-years) was comparable to data reported in the literature from developing countries. Our series reported a significant male predominance; male-to-female ratio was 4:1 which was higher than 3:1 which was reported in the literature from developing countries. ${ }^{3,6}$ In North American literature there is not much difference between the sexes. ${ }^{7}$ Non-specific abdominal pain $(34.5 \%)$ and classic renal colic $(31.0 \%)$ were the most common clinical manifestations, which were similar to most literature. ${ }^{1-7}$ In our series, positive family history was found in $13.7 \%$ of the children and $75 \%$ of patients with metabolic changes. It is known from various series that about $20-40 \%$ of children with urolithiasis have a positive family history, compared to that our series had a lesser percentage of patients with a positive family history $(13.7 \%)^{3-5}$ According to a study by Naseri et al positive family history was found in $62.7 \%$ of patients with kidney stones who were prospectively evaluated. ${ }^{8}$ A retrospective study by Vandervoort et al also demonstrated positive family history in half of the cases evaluated, showing the important role of family history in paediatric urolithiasis.?

Hematuria was the most common finding in urine analysis followed by leukocyturia which was comparable with 
a study by Kroovand $\mathrm{RL}^{10}$ In our series patients had undergone a varied spectrum of imaging investigations from abdominal ultrasonography to CT and renal scintigraphy. Though noncontrast abdominal CT scan is considered gold standard imaging investigation for stone disease, in paediatric age group it has its own disadvantages like the need for sedation, concern over longterm effects of radiation exposure and availability. In our series, most common imaging modality was abdominal ultrasonography, as it was economical and not associated with radiation or contrast exposure. In our series $96.5 \%$ of patients had undergone abdominal ultrasonography compared to $97.2 \%$ reported by Amancio et al. ${ }^{4}$ Non-contrast abdominal CT scan which is considered as a gold standard imaging modality, in our series $44.8 \%$ patients had undergone non-contrast abdominal CT scan which is significantly higher compared to $31.1 \%$ and $7 \%$ reported by Luana Amancio et al. ${ }^{4}$ and Kit et al ${ }^{11}$ respectively.

The mean stone size was $13.2 \pm 7.0 \mathrm{~mm}$ which is similar compared to $16 \pm 8.0 \mathrm{~mm}$ reported by Rizvi et $\mathrm{al}^{6}$ from Karachi, but compared to western literature it is significantly higher. Bilateral stone disease occurred in $20.6 \%$ of patients which is significantly higher compared to literature and was more common in patients having metabolic abnormalities. ${ }^{1,5,6}$ Nephrocalcinosis was seen in $3.4 \%$ patients which was comparable to data reported by Amancio et $\mathrm{al}^{4}{ }^{4}$ In our series there was not much difference in laterality similar to reports in the literature. As for the location of stones, they were predominantly upper urinary stones. A retrospective study from Pakistan by Rizvi et $\mathrm{al}^{6}$ reported 69\% upper urinary tract stones and 31\% lower urinary tract stones. Our series was more comparable with western literature than above study from Pakistan and other literature form developing nations. ${ }^{4-6}$ The majority of urinary stones were located in the upper urinary tract $(93 \%)$ (Table 3). This result is similar to the findings of other recent studies. Similar to the findings found in this series, other authors have reported lower rates of lower urinary tract stones. In recent years, the pattern of paediatric stone disease has changed in developing countries, the incidence of lower urinary tract stones have decreased considerably and are more in line with western statistics, as seen in our series. ${ }^{1,4-8}$

A retrospective study on paediatric urolithiasis by Amancio et $\mathrm{al}^{4}$ reported anatomic abnormalities 15 patients $(14.2 \%)$, and among them, pelvi-ureteric junction stenosis was the most common. Kit et al ${ }^{11}$ also reported similar data of $14 \%$ having an anatomic genitourinary abnormality concurrent with stone disease. The above literature is comparable to our series which showed anatomic abnormalities in 5 patients (17.2\%), and among them, pelvi-ureteric junction obstruction was the most common. ${ }^{4,11}$

Urinary tract infection on initial presentation was found in $17.2 \%$ of our patients, more in the male gender. Main agents were Escherichia coli (40.0\%) and Enterococcus fecalis (40.0\%). The rates of UTI in our series was comparable to western literature but was significantly less compared to literature from developing countries. ${ }^{1,-8}$ Rizvi et $\mathrm{al}^{4}$ from Pakistan reported a culture-positive rate of $46 \%$ on presentation which is considerably high compared to our series. ${ }^{6}$ Enterococcus fecalis is fairly uncommon in the available literature, but $40.0 \%$ patients in our series with UTI had grown Enterococcus fecalis in urine culture..$^{4-8}$

Stone analysis was done in 11 patients $(37.9 \%)$, calcium containing stones were predominant. Most common were calcium oxalate and calcium phosphate stones. Calcium oxalate and phosphate stones accounted for $81.8 \%$. A retrospective study by Rellum et $\mathrm{al}^{5}$ from the Netherlands reported 59\% calcium oxalate and phosphate stones, while Bak et $\mathrm{al}^{12}$ from Turkey reported $86 \%$. All patients were metabolically evaluated, 16 patients $(55.2 \%)$ had metabolic abnormalities. Most common abnormality was hypocitraturia $(37.5 \%)$ followed by hypercalciuria $(31.2 \%)$ and hyperoxaluria $(18.7 \%)$. Several authors have reported that hypercalciuria is seen in 72 to $88 \%$ of paediatric stone patients. Rizvi et $\mathrm{al}^{6}$ from Pakistan reported hypocitraturia (63\%) as the most common abnormality. While Coward et $\mathrm{al}^{13}$ from the United Kingdom and Alpay et $\mathrm{al}^{14}$ from Turkey reported hypercalciuria (57\% and $34 \%$ ) as the most common abnormality respectively. Our findings are partly comparable to that of Rizvi et $\mathrm{al}^{6}$ and Rellum et $\mathrm{al}^{5}$ these mild variations maybe because the $24 \mathrm{hr}$ urine metabolic reference values are based on western literature (Table 4).

Our study reported a spontaneous elimination rate of $6.9 \%$. Van Savage et $\mathrm{al}^{15}$ showed a reduction in spontaneous elimination of paediatric stone disease when stones were larger than $3 \mathrm{~mm}$. Few other studies by Pietrow et $\mathrm{al}^{16}$ and Kit et $\mathrm{al}^{11}$ showed reduced spontaneous elimination when stone size was more than $4 \mathrm{~mm}$. The average size of all stones evaluated in our study was $13.2 \pm 7.0 \mathrm{~mm}$, a significantly higher value than compared to studies by Pietrow et $\mathrm{a}^{16}$ and Kit et $a{ }^{11}{ }^{11}$ this could explain the lower spontaneous elimination than compared to literature. Moreover, this subset of the population which is a part of our study may represent patients who sought medical care were more

\begin{tabular}{|c|c|c|c|c|c|c|c|c|c|c|c|c|c|}
\hline Country & Authors & Period & $\begin{array}{c}\text { Age } \\
\text { (years) }\end{array}$ & $\begin{array}{c}\text { No. of Metabolic } \\
\text { Analyses Unt }\end{array}$ & $\begin{array}{l}\text { Met. } \\
\text { \# (\%) }\end{array}$ & $\begin{array}{l}\uparrow \mathrm{Ca} \\
(\%)\end{array}$ & $\begin{array}{l}\downarrow \mathbf{C i} \\
\text { (\%) }\end{array}$ & $\begin{array}{l}\downarrow \mathbf{M g} \\
(\%)\end{array}$ & $\begin{array}{l}\uparrow \mathbf{P} \\
\mathbf{( \% )}\end{array}$ & $\begin{array}{l}\uparrow U r \\
\text { (\%) }\end{array}$ & $\begin{array}{l}\uparrow O x \\
\text { (\%) }\end{array}$ & $\begin{array}{l}\uparrow \text { Cys } \\
\text { (\%) }\end{array}$ & $\begin{array}{c}\text { NOS } \\
(\%)\end{array}$ \\
\hline Pakistan & Rizvi et al ${ }^{6}$ & $1987-2000$ & $0-14$ & $154 / 1440$ & 93 & 11 & 63 & 51 & & 27 & 40 & & \\
\hline UK & $\begin{array}{l}\text { Coward et } \\
\mathrm{al}^{13}\end{array}$ & $|997-200|$ & $0-15$ & $|2| /|2|$ & 44 & 57 & & & & 2 & 7 & 23 & 2 \\
\hline Turkey & Alpay et $\mathrm{al}^{14}$ & $1998-2008$ & $0-16$ & $162 / 162$ & 87 & 34 & 33 & & 21 & 25 & 27 & 6 & \\
\hline Netherlands & Rellum et $\mathrm{al}^{5}$ & $1996-2010$ & $0-19$ & $49 / 71$ & 84 & 44 & 25 & 6 & & 8 & 29 & 8 & \\
\hline India & Current study & $2009-2019$ & $0-18$ & $29 / 29$ & 55 & 31 & 38 & & 3 & 12 & 19 & & \\
\hline
\end{tabular}


symptomatic and with worse complications.

Ureteroscopic extraction and ESWL were the most common surgical interventions done in our study. The rates of PCNL were lower in our study compared to literature, this may be attributed to the newer treatment modality of RIRS which is not reported in most of the Indian literature. Most of the recent literature reports a major shift from an open surgical approach to minimally invasive and endourological approach to paediatric urolithiasis, which is evident in our study as well. Clearance rates for following procedures, ureteroscopic extraction, ESWL, PCNL, PCCL, and RIRS were comparable to most studies. ${ }^{1,-8,15}$

The main objective of treatment of paediatric urolithiasis and more importantly in the subset with metabolic abnormalities is to reduce or prevent the formation of new stones or prevent existing ones to increase in size, thus aiming to reduce morbidity and the requirement for surgical intervention. This includes nonpharmacological and pharmacological treatments. The most important approach includes the increase in urine output resulting from increased fluid intake and dietary modifications. However, children rarely adhere to such approaches and pharmacological intervention is essential in most instances to achieve a reduction in recurrence rates. ${ }^{4-8}$ Pharmacological treatment was instituted in $75 \%$ of the patients, mostly who had hypocitraturia or hypercalciuria. Most commonly used were potassium citrate and thiazide diuretic in a few patients.

Recurrent stones were seen in $11(37.9 \%)$, among them $8(72.7 \%)$ of them had metabolic disorders and $3(27.2 \%)$ patients had no metabolic changes. Amancio et $\mathrm{al}^{4}$ reported stone recurrence rates of $20.2 \%$ and $\mathrm{Kit}$ et $\mathrm{al}^{11}$ of $24 \%$ respectively, which was comparatively lower compared to our study. ${ }^{4}$ A stone recurrence rate of $72.7 \%$ in children with metabolic abnormalities is also comparatively much higher than similar studies like Vandervoort et $\mathrm{al}^{9}$ and Koyuncu et $\mathrm{al}^{17}$ who reported 39\% and $50 \%$ respectively. This comparatively higher recurrence rate in our study maybe attributed to poor adherence to pharmacological treatment and diet modifications, or moreover, since the patients in the study represent the subset of the population who were more symptomatic and had a complicated paediatric stone disease. Limitation of our study includes that the study group represent a small subset of the representative population, patients who presented for treatment at our centre were more symptomatic and had a more complicated disease. More prospective multicentre studies are needed to shed better light on paediatric stone disease and provide a solution for the paucity of literature in the Indian setting, more so from nonendemic regions of stone disease.

\section{CONCLUSION}

Paediatric urolithiasis is an emerging disease in India but a rarer entity compared to its adult counterpart. There is a high prevalence of metabolic abnormalities as an etiological factor in paediatric stone disease which supports the need for metabolic evaluation in all cases. There is more similarity of our study with Western literature than the available Indian data (Predominantly from North India) which may be due to the lifestyle changes, significant geographic variation within India itself between endemic and nonendemic regions or changing epidemiology of paediatric stone disease per se. ${ }^{4,5,18-20}$ There is a strong need for Indian reference values adjusted to the specific region demographics for metabolic testing to curtail overtreatment as well as undertreatment and aid in follow-up for those on pharmacological treatment. Despite limitations, the results of this study give a valid insight into the paediatric stone disease (non-endemic region) in a subset of the South Indian population.

\section{ETHICS APPROVAL AND CONSENT TO PARTICIPATE}

Informed consent has been taken from the patient for this study.

\section{AVAILABILITY OF DATA AND MATERIAL}

Datasets obtained and analysed in the current study are available upon request from the corresponding author.

\section{AUTHORS' CONTRIBUTION}

Dr. KMBV was responsible for framing the concept and study design, was instrumental in literature search, data acquisition, statistical analysis, result analysis, and manuscript preparation. Dr. RR played a key role in developing the concept and study design, helped in data analysis, results, forming conclusions, preparing and reviewing the manuscript. Dr. AT guided the formulation of conclusions, played a pivotal role in manuscript preparation, editing and review. Dr. AM was instrumental in reviewing the data and statistical analysis, helped in formulation of results and conclusions, reviewed the manuscript and gave valuable inputs from the Nephrology perspective. All authors read and approved the final manuscript and revisions for submission. All authors agreed to be personally accountable for their own contributions and ensure that questions related to the accuracy or integrity of any part of the work, even ones in which they were not personally involved, are appropriately investigated, resolved, and the resolution documented in the literature. All authors read and approved the final manuscript.

\section{FUNDING}

This study received no funding from any source.

\section{ACKNOWLEDGEMENTS}

Not applicable.

\section{CONFLICTS OF INTEREST}

The authors declare that they have no conflicts of interest.

\section{REFERENCES}

1. Edvardsson V. Urolithiasis in children. In: Pediatric Nephrology. $7^{\text {th }}$ ed. Heidelberg, Germany: Springer Berlin Heidelberg; 2016: 1821 1868. doi: 10.1007/978-3-662-43596-0_53 
2. Gajengi AKR, Wagaskar VG, Tanwar HV, Mhaske S, Patwardhan SK. Metabolic evaluation in paediatric urolithiasis: A 4-year open prospective study. J Clin Diagnostic Res. 2016; 10(2): PC04-PC06. doi: 10.7860/JCDR/2016/17265.7251

3. Rizvi SAH, Sultan S, Zafar MN, Ahmed B, Aba Umer S, Naqvi SAA. Paediatric urolithiasis in emerging economies. Int J Surg. 2016; 36: 705-712. doi: 10.1016/j.ijsu.2016.11.085

4. Amancio L, Fedrizzi M, Bresolin NL, Penido MGMG. Pediatric urolithiasis: experience at a tertiary care pediatric hospital. J Bras Nefrol. 2016; 38(1): 90-98. doi: 10.5935/0101-2800.20160014

5. Rellum DM, Feitz WF, Van Herwaarden AE, Schreuder MF. Pediatric urolithiasis in a non-endemic country: A single center experience from the Netherlands. J Pediatr Urol. 2014;10: 155-161. doi: 10.1016/j.jpurol.2013.07.019

6. Rizvi SAH, Naqvi SAA, Hussain Z, Hashmi A, Hussain M, Zafar $\mathrm{MN}$, et al. Pediatric urolithiasis: Developing nation perspectives. J Urol. 2002;168: 1522-1525. doi: 10.1097/01. ju.0000028601.63446.51

7. Moreira Guimarães Penido MG, de Sousa Tavares M. Pediatric primary urolithiasis: Symptoms, medical management and prevention strategies. World J Nephrol. 2015; 4(4): 444-454. doi: 10.5527/wjn.v4.i4.444

8. Naseri M, Varasteh AR, Alamdaran SA. Metabolic factors associated with urinary calculi in children. Iran J Kidney Dis. 2010; 4(1): 32-38.

9. Van Dervoort K, Wiesen J, Frank R, Vento S, Crosby V, Chandra $\mathrm{M}$, et al. Urolithiasis in pediatric patients: A single center study of incidence, clinical presentation and outcome. J Urol. 2007; 177(6): 2300-2305. doi: 10.1016/j.juro.2007.02.002

10. Kroovand RL. Pediatric urolithiasis. Urol Clin North Am. 1997; 24: 173-184. doi: 10.1016/s0094-0143(05)70362-1

11. Kit LC, Filler G, Pike J, Leonard MP. Pediatric urolithiasis:
Experience at a tertiary care pediatric hospital. J Can Urol Assoc. 2008; 2(4): 381-386. doi: 10.5489/cuaj.804

12. Bak M, Ural R, Agin H, Serdaroglu E, Calkavur S. The metabolic etiology of urolithiasis in Turkish children. Int Urol Nephrol. 2009; 41(3): 453-460. doi: 10.1007/s11255-008-9513-x

13. Coward RJM, Peters CJ, Duffy PG, Corry D, Kellett MJ, Choong $\mathrm{S}$, et al. Epidemiology of paediatric renal stone disease in the UK. Arch Dis Child. 2003; 88: 962-965. doi: 10.1136/adc.88.11.962

14. Alpay H, Ozen A, Gokce I, Biyikli N. Clinical and metabolic features of urolithiasis and microlithiasis in children. Pediatr Nephrol. 2009; 24: 2203-2209. doi: 10.1007/s00467-009-1231-9

15. Van Savage JG, Palanca LG, Andersen RD, Rao GS, Slaughenhoupt BL. Treatment of distal ureteral stones in children: Similarities to the American Urological Association guidelines in adults. J Urol. 2000; 164(3 II): 1089-1093. doi: 10.1097/00005392200009020-00043

16. Pietrow PK, Pope IV JC, Adams MC, Shyr Y, Brock JW. Clinical outcome of pediatric stone disease. J Urol. 2002; 167(2 I): 670-673. doi: 10.1097/00005392-200202000-00060

17. Koyuncu H, Yencilek F, Erturhan S, Eryildirım B, Sarica K. Clinical course of pediatric urolithiasis: Follow-up data in a longterm basis. Int Urol Nephrol. 2011; 43(1): 7-13. doi: 10.1007/s11255010-9791-y

18. Hari P, Bagga A, Vasudev V, Singh M, Srivastava RN. Aetiology of nephrolithiasis in north Indian children. Pediatr Nephrol. 1995; 9(4): 474-475. doi: 10.1007/BF00866731

19. Bakane BC, Nagtilak SB, Patil B. Urolithiasis : A tribal scenario. Indian J Pediatr. 1999; 66(6): 863-865. doi: 10.1007/BF02723855

20. Shah AM, Kalmunkar S, Punekar S V, Billimoria FR, Bapat SD, Deshmukh SS. Spectrum of pediatric urolithiasis in western India. Indian J Pediatr. 1991; 58(4): 543-549. doi: 10.1007/BF02750939 